\title{
Breast magnetic resonance imaging for surveillance of women with a personal history of breast cancer: outcomes stratified by interval between definitive surgery and surveillance MR imaging
}

\author{
Vivian Youngjean Park, Eun-Kyung Kim, Min Jung Kim, Hee Jung Moon and Jung Hyun Yoon * (D)
}

\begin{abstract}
Background: Women with a personal history of breast cancer are at increased risk of future breast cancer events, and may benefit from supplemental screening methods that could enhance early detection of subclinical disease. However, current literature on breast magnetic resonance (MR) imaging surveillance is limited. We investigated outcomes of surveillance breast magnetic resonance (MR) imaging in women with a personal history of breast cancer.

Methods: We reviewed 1053 consecutive breast MR examinations that were performed for surveillance in 1044 women (median age, 53 years; range, 20-85 years) previously treated for breast cancer between August 2014 and February 2016. All patients had previously received supplemental surveillance with ultrasound. Cancer detection rate (CDR), abnormal interpretation rate and characteristics of MR-detected cancers were assessed, including extramammary cancers. We also calculated the PPV $1, \mathrm{PPV}_{3}$, sensitivity and specificity for MR-detected intramammary lesions.

Performance statistics were stratified by interval following initial surgery.

Results: The CDR for MR-detected cancers was 6.7 per 1000 examinations (7 of 1053) and was 3.8 per 1000 examinations (4 of 1053) for intramammary cancers. The overall abnormal interpretation rate was $8.0 \%$, and the abnormal interpretation rate for intramammary lesions was 7.2\%. The PPV $1, P P V_{3}$, sensitivity and specificity for intramammary lesions was 5.3\% (4 of 76), 15.8\% (3 of 19), 75.0\% (3 of 4) and 98.3\% (1031 of 1049), respectively. For MR examinations performed $\leq 36$ months after surgery, the overall CDR was 1.4 per 1000 examinations. For MR examinations performed > 36 months after surgery, the overall CDR was 17.4 per 1000 examinations.

Conclusions: Surveillance breast MR imaging may be considered in women with a history of breast cancer, considering the low abnormal interpretation rate and its high specificity. However, the cancer detection rate was low and implementation may be more effective after more than 3 years after surgery.
\end{abstract}

Keywords: Breast cancer, Surveillance, Magnetic resonance imaging

\footnotetext{
* Correspondence: Ivjenny@yuhs.ac

Department of Radiology and Research Institute of Radiological Science,

Severance Hospital, Yonsei University College of Medicine, 50-1 Yonsei-ro,

Seodaemun-gu, 03722 Seoul, Republic of Korea
} 


\section{Background}

Although women previously treated for breast cancer are at a statistically significant increased risk of future breast cancer events [1, 2], annual mammographic screening is currently the only post-treatment imaging modality recommended for breast cancer follow-up by the American Society for Clinical Oncology (ASCO) and the National Comprehensive Cancer Network (NCCN) [3, 4].

There has been limited information on breast magnetic resonance (MR) imaging surveillance in this specific patient population. Previous screening trials using MR imaging have focused on high-risk women without a personal history of breast cancer, resulting in increased invasive breast cancer yields at acceptable recall rates and positive predictive values (PPV) of biopsy [5-8]. Surveillance breast MR imaging may also have potential benefits in women previously treated for breast cancer, primarily by overcoming the decreased sensitivity of mammography in breasts with dense tissue and treatment-related changes [9-11]. Despite advances in locoregional and systemic therapy, recurrence or second breast cancer rates are approximately 3\% to 5\% per year even in early-stage hormone receptor-positive patients $[2,12]$. Therefore, this patient group would benefit from supplemental screening methods that could enhance early detection of subclinical disease and ultimately improve relative survival $[13,14]$. Previous studies have reported that breast MR imaging depicted additional cancers even after prior or concurrent negative findings of mammography and ultrasound (US) $[11,15,16]$. However, due to sparse data on surveillance breast MR imaging, the appropriate interval following surgery for initiation of MRI surveillance has not yet been investigated.

At our institution, surveillance breast MR imaging has recently been implemented as part of the routine posttreatment surveillance protocol for patients previously treated for breast cancer. These patients had previously undergone routine supplemental surveillance with US. As a result, we were able to obtain data from a large group of patients regarding its performance stratified by interval between definitive surgery and implementation of MRI surveillance. The purpose of this study was to investigate the outcomes of surveillance breast MR imaging in women with a personal history of breast cancer.

\section{Methods}

\section{Study population}

This retrospective study was approved by the institutional review board of Yonsei University College of Medicine and the requirement for informed consent was waived. Between August 2014 and February 2016, 1285 breast MR examinations were performed in 1266 women who had been previously treated for breast cancer, either with breast conserving surgery (BCS) $(n=648)$ or mastectomy $(n=396)$. Among them, 222 women were excluded either because they underwent MR imaging for reasons other than postoperative surveillance $(n=70)$; they had BRCA genetic mutations $(n=20)$; they had undergone screening breast MR imaging prior to the study period $(n=4)$; or their 12 -month imaging followup information was unavailable $(n=128)$ (Fig. 1$)$. Finally, 1053 breast MR examinations that were performed for surveillance in 1044 women (median age, 53 years; range, 20-85 years) with a personal history of breast cancer composed our study population. Among them, 9 women underwent two rounds of screening $\mathrm{MR}$ examinations during the study period. Analysis of Breast Imaging Reporting and Data System (BI-RADS) category assessments of mammograms and US performed prior to MR examinations revealed BI-RADS category 1 in 373 examinations (35.4\%), category 2 in 434 examinations (41.2\%), and category 3 in 246 examinations (23.4\%). The median follow-up period after surveillance breast MR imaging was 18.7 months (range, 12.0-30.7 months).

\section{Post-treatment surveillance}

After definitive breast cancer surgery, patients underwent follow-up by clinical examination and breast US every 6 months and with mammography, chest radiography, abdominal US and whole body bone scan every 12 months. After 5 years following initial surgery, patients underwent annual follow-up by breast US and mammography. Breast MR imaging was implemented as part of the routine posttreatment surveillance protocol in 2013, and thereafter patients underwent screening breast MR imaging instead of US at approximately two and five years after surgery. Surveillance breast MR imaging was also performed at the request of clinicians or patients.

The median interval between prior surveillance US and MR examinations was 6.1 months (range, 013.9 months). In 19 cases (1.8\%), surveillance US and MR imaging were performed on the same day at the

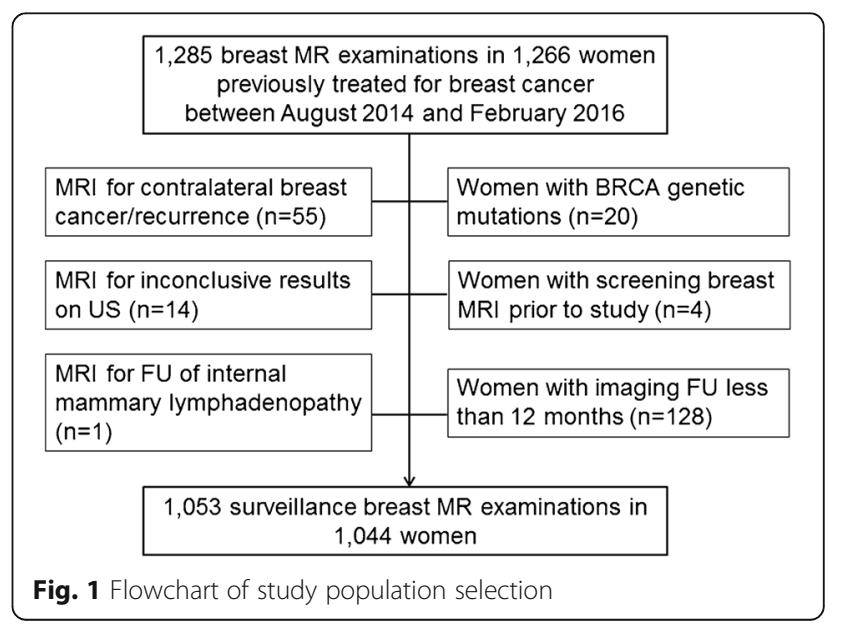


request of the referring physician. The median interval between prior mammography and MR examinations was 11.5 months (range, 0-65.1 months).

\section{MR imaging technique}

Breast MR examinations were performed using two 3 Tesla MR scanners (Discover 750, GE Medical Systems, Milwaukee, WI, USA; Ingenia, Philips Medical Systems, Best, The Netherlands). Imaging was performed with a dedicated phased array breast coil (8-channel GE or 16channel Philips) with the patient in the prone position. Imaging was performed prior to a rapid bolus injection of contrast agent and six times after injection. Sequences included a three-plane localizing sequence, axial T2weighted fast-spin-echo and T2-stimulated inversion recovery (STIR) sequence, and axial T1-weighted nonfat-suppressed or fat-suppressed sequence before contrast administration. The bolus injection consisted of $0.2 \mathrm{mmol} / \mathrm{kg}$ body weight of gadolinium-based contrast agent (Dotarem, Guerbet, Paris, France; Magnevist, Berlex Laboratories, Wayne, NJ, USA; or Gadovist, Bayer Scherming Pharma, AG, Berlin, Germancy) and a 20-mL saline flush delivered at a rate of $2 \mathrm{ml} / \mathrm{s}$. 3D dynamic post-contrast enhanced (DCE) axial images are then performed in the axial plane and a T1-weighted 3D delayed postcontrast sequence is acquired in the sagittal plane. Bilateral examinations were performed for all patients.

\section{MR imaging evaluation}

MR images were prospectively interpreted by one of four radiologists with 6-15 years of experience in breast MR imaging interpretation. Computer aided evaluation software (CADstream, Confirma, Kirkland, WA) was used for characterization of lesion kinetics. Of the 1044 women, 89.1\% (930 of 1044) previously underwent preoperative MR imaging. Each MR examination was given a Breast Imaging Reporting and Data System (BI-RADS) final assessment category based on the breast lesion morphology and kinetics.

We retrospectively reviewed MR imaging reports, clinical and imaging records. For lesions assessed as BI-RADS 3, follow-up breast MRI or US at 612 months was recommended based on the presence of a US-correlate on previous imaging and the period of stability. BI-RADS category 3 was also given to newly found lesions if its findings were probably benign according to the BI-RADS MR lexicon [17]. For breast or chest wall lesions that were assessed as BIRADS category 4 or 5 , targeted US was first performed and US-guided biopsy or MR-guided biopsy was performed accordingly. For suspicious extramammary findings found on breast MR imaging, further evaluation with other imaging modalities was performed with subsequent biopsy when needed.

\section{Statistical analysis}

Intramammary cancer was defined as cancer in the ipsilateral breast following BCS or cancer in the contralateral breast. Extramammary cancer was defined as locoregional disease (cancer in the ipsilateral axilla, internal mammary or supraclavicular lymph nodes or in the mastectomy bed) and distant metastasis.

We calculated the overall cancer detection rate and abnormal interpretation rates. The overall cancer detection rate for MRI was defined as the total number of intramammary and extramammary cancers detected at MR imaging per 1000 examinations. The overall abnormal interpretation rate for MRI was defined as the percentage of MR examinations that were given BI-RADS categories $0,3,4,5$ or those with findings suspicious for extramammary cancer detected at MR imaging. According to the outcome monitoring section of the BI-RADS 5 th edition atlas, we included BI-RADS category 3 in the numerator of the abnormal interpretation rate because further imaging is recommended before the next routine screening [18].

We also calculated outcome measures for MRdetected intramammary lesions. The cancer detection rate for intramammary lesions was defined as the total number of intramammary cancers detected at MR imaging per 1000 examinations. The abnormal interpretation rate for intramammary lesions was defined as the percentage of MR examinations that were given BIRADS categories $0,3,4$, or 5 . Positive MR examinations were defined as those given BI-RADS categories 4 or 5 . Negative MR examinations were defined as those assessed as BI-RADS categories 1, 2 or 3. MR examinations with an initial BI-RADS category 0 assessment were reclassified according to their final assessment. $\mathrm{PPV}_{1}$ was defined as the percentage of MR examinations with BI-RADS categories $0,3,4,5$ that resulted in a tissue diagnosis of cancer. $\mathrm{PPV}_{3}$ was defined as the percentage of all known breast biopsies performed as a result of positive MR examinations that resulted in a tissue diagnosis of cancer. A true-positive (TP) result was defined as a positive MR examination resulting in a diagnosis of cancer within 1 year. A true-negative (TN) result was defined as a negative MR examination and no detection of cancer within 1 year. A false-negative (FN) result was defined as a negative MR examination with a diagnosis of cancer within 1 year. A false-positive (FP) result was defined as a positive MR examination with no detection of cancer within 1 year.

In addition, we stratified the above performance statistics according to the interval between initial surgery and surveillance MR imaging: (1) for MR examinations performed at or less than a 36-month interval and (2) for examinations performed at more than a 36-month interval following initial surgery. Performance statistics were 
compared between the two groups using the Fisher exact test. We also compared the intervals between prior surveillance US and MR examinations by using the Student $t$ test. Statistical analyses were performed by using statistical software (SPSS version 23.0; IBM Corp, Armonk, NY.).

\section{Results}

Table 1 shows the clinical-pathologic characteristics of the 1044 women who underwent screening breast MR examinations. The median interval between initial surgery for

Table 1 Characteristics of 1044 women with a personal history of breast cancer

\begin{tabular}{|c|c|}
\hline Characteristic & \\
\hline Age (years) ${ }^{a}$ & $53(20-85)$ \\
\hline $\begin{array}{l}\text { Interval between initial surgery } \\
\text { and screening MRI (months) }\end{array}$ & $27.8(12.1-167.3)$ \\
\hline \multicolumn{2}{|l|}{ Preoperative breast MRI } \\
\hline Yes & $930(89.1 \%)$ \\
\hline No & $114(10.9 \%)$ \\
\hline \multicolumn{2}{|l|}{ Pathology of initial breast cancer } \\
\hline Ductal carcinoma in situ & 185 (17.7\%) \\
\hline Invasive ductal carcinoma & 729 (69.8\%) \\
\hline Invasive lobular carcinoma & $33(3.2 \%)$ \\
\hline Tubular carcinoma & $25(2.4 \%)$ \\
\hline Cribiform carcinoma & $3(0.3 \%)$ \\
\hline Mucinous carcinoma & $23(2.2 \%)$ \\
\hline Invasive micropapillary carcinoma & $6(0.6 \%)$ \\
\hline Metaplastic carcinoma & $6(0.6 \%)$ \\
\hline Solid papillary carcinoma & $10(1.0 \%)$ \\
\hline Others & $24(2.3 \%)$ \\
\hline \multicolumn{2}{|l|}{ Type of surgery } \\
\hline Partial mastectomy & $648(62.1 \%)$ \\
\hline Mastectomy & $396(37.9 \%)$ \\
\hline \multicolumn{2}{|l|}{ Pathological T stage } \\
\hline TX & $15(1.4 \%)$ \\
\hline TO & $27(2.6 \%)$ \\
\hline Tis & $188(18.0 \%)$ \\
\hline $\mathrm{T} 1$ & $624(59.8 \%)$ \\
\hline $\mathrm{T} 2$ & $176(16.9 \%)$ \\
\hline T3 & $12(1.1 \%)$ \\
\hline T4 & $2(0.2 \%)$ \\
\hline \multicolumn{2}{|l|}{ Pathological N stage } \\
\hline NX & $7(0.7 \%)$ \\
\hline No & $822(78.7 \%)$ \\
\hline N1 & $182(17.4 \%)$ \\
\hline N2 & $27(2.6 \%)$ \\
\hline N3 & $6(0.6 \%)$ \\
\hline
\end{tabular}

${ }^{a}$ Median value is shown with range in parentheses breast cancer and first-time screening MR examination was 27.8 months (range, 12.1-167.3 months). The final assessment categories of the 1053 examinations were as follows: BI-RADS category 1 in 545 examinations (51.8\%), BI-RADS category 2 in 432 examinations (41.0\%), BIRADS category 3 in 54 (5.1\%), BI-RADS category 4 in 21 examinations (2.0\%), BI-RADS category 0 in 1 examination (0.1\%). Three examinations assigned as BI-RADS category 2 and five examinations assigned as BI-RADS category 1 showed extramammary findings suspicious for malignancy $(0.8 \%, 8$ of 1053$)$.

\section{Cancer detection yield for MRI}

The overall abnormal interpretation rate for MRI was $8.0 \%$ (84 of 1053) and biopsy or further imaging was recommended for 29 examinations (2.7\%) with 21 of the 29 exams classified as BI-RADS category 4 and the other 8 exams demonstrating extramammary lesions suspicious for malignancy (Table 2). Of the 21 BI-RADS category 4 lesions, 18 lesions underwent image-guided biopsy (USguided biopsy [ $n=16]$ or MR-guided biopsy $[n=2]$ ) and one lesion underwent surgical excision for a US correlate. Among them, 3 lesions were diagnosed as cancer. All three detected cancers were newly developed contralateral breast cancer, with one cancer detected at a second-round MR examination. Of the 54 lesions that were BI-RADS category 3 , one cancer was diagnosed $(1.8 \%)$. This lesion was an $8-\mathrm{mm}$ enhancing mass at the contralateral breast and moderate background parenchymal enhancement on preoperative MR imaging performed 5 years ago made accurate comparison difficult. Because it was considered to have slightly increased in size, ultrasound correlation was recommended and the final assessment was upgraded to BI-RADS category 4 at US. Subsequent US-guided biopsy yielded invasive ductal carcinoma (Table 3). All of the four MR-detected intramammary cancers were not detected on prior surveillance US which was performed at a median interval of 5.5 months (range, 4.6-12.4 months).

Among the 8 examinations with suspicious extramammary findings, five were finally considered negative based on image-guided biopsy $(n=3)$ or further imaging evaluation (PET-CT, whole body bone scan) $(n=2)$ with no evidence of malignancy for more than 1 year. Of the three examinations with extramammary cancer, two were histologically confirmed by US-guided biopsy ( $n=1$, chest wall) or surgical excision $(\mathrm{n}=1$, mediastinal $\mathrm{LN})$. The remaining one patient was diagnosed with sternum metastasis based on imaging alone, which was initially detected on breast MRI and subsequently confirmed by whole body bone scan and PET-CT (Table 4). Therefore, the overall cancer detection rate for MRI was 6.7 per 1000 examinations (7 of 1053). 
Table 2 Performance of surveillance breast MR imaging

\begin{tabular}{|c|c|c|c|c|}
\hline Performance Statistics & $\begin{array}{l}\text { Total } \\
(n=1053)\end{array}$ & $\begin{array}{l}\text { Initial surgery-MR } \\
\text { interval } \leq 36 \text { months } \\
(n=709)\end{array}$ & $\begin{array}{l}\text { Initial surgery-MR } \\
\text { interval > } 36 \text { months } \\
(n=344)\end{array}$ & $p$ value \\
\hline Cancer detection rate for $\mathrm{MRI}^{\mathrm{a}}$ & $6.7(7 / 1053)$ & $1.4(1 / 709)$ & $17.4(6 / 344)$ & 0.006 \\
\hline Abnormal interpretation rate for MRI & $84 / 1053(8.0 \%)^{c}$ & $51 / 709(7.2 \%)$ & $33 / 344(9.6 \%)$ & 0.184 \\
\hline $\begin{array}{l}\text { Cancer detection rate for } \\
\text { intramammary lesions }^{\mathrm{b}}\end{array}$ & $3.8(4 / 1053)$ & $1.41(1 / 709)$ & $8.7(3 / 344)$ & 0.105 \\
\hline $\begin{array}{l}\text { Abnormal interpretation rate } \\
\text { for intramammary lesions }\end{array}$ & $76 / 1053(7.2 \%)$ & 49/709 (6.9\%) & $27 / 344(7.8 \%)$ & 0.612 \\
\hline $\mathrm{PPV}_{1}$ & $4 / 76(5.3 \%)$ & $1 / 49(2.0 \%)$ & $3 / 27(11.1 \%)$ & 0.125 \\
\hline $\mathrm{PPV}_{3}$ & $3 / 19(15.8 \%)$ & $1 / 10(10.0 \%)$ & $2 / 9(22.2 \%)$ & 0.582 \\
\hline Sensitivity & $3 / 4(75.0 \%)$ & $1 / 1(100 \%)$ & $2 / 3(66.7 \%)$ & $>0.999$ \\
\hline Specificity & 1031/1049 (98.3\%) & 698/708 (98.6\%) & $333 / 341(97.6 \%)$ & 0.199 \\
\hline
\end{tabular}

${ }^{a}$ Cancer detection rate for MRI is total number of intramammary and extramammary cancers detected at MR imaging per 1000 examinations

${ }^{b}$ Cancer detection rate for intramammary lesions is total number of total number of intramammary cancers detected at MR imaging per 1000 examinations

'Percentage is shown in parentheses

\section{Cancer detection yield for Intramammary lesions}

The abnormal interpretation rate for MR-detected intramammary lesions was $7.2 \%$ (76 of 1053) and the cancer detection rate for intramammary lesions was 3.8 per 1000 examinations (4 of 1053). The $\mathrm{PPV}_{1}$ was $5.3 \%$ (4 of 76) and $\mathrm{PPV}_{3}$ was $15.8 \%$ (3 of 19). There was only one falsenegative result during the study period, corresponding to the aforementioned invasive ductal carcinoma assigned as category 3 . The sensitivity of surveillance MR imaging was $75.0 \%$ (3 of 4 [95\% confidence interval: $71.0 \%, 79.0 \%]$ ) and the specificity was $98.3 \%$ (1031 of 1049 [95\% confidence interval: $97.1 \%, 99.5 \%])$.

\section{Cancer detection yield according to interval between initial surgery and MRI}

The overall cancer detection rate for MRI was significantly greater in MR examinations performed with more than a 36-month interval following initial surgery than those performed at or less than a 36-month interval (17.4 per 1000 examinations vs. 1.4 per 1000 examinations, $p=0.006)$. None of the other performance statistics showed a significant difference between the two groups (Table 2).
The mean interval between prior US and MR examinations was slightly greater in MR examinations performed $\leq 36$ months than those performed $>36$ months following initial surgery $(6.3 \pm 1.0$ months vs. 5.9 months \pm 1.6 months, $p<0.001$ ), but with a mean difference of 0.4 months.

\section{Discussion}

With recognition of the increased future breast cancer risk in patients with a personal history of treated breast cancer and the decreased sensitivity of mammography in dense breasts, several studies have recently investigated the performance of surveillance breast MRI examinations [15, 19-23]. Although the patient population and study design differ somewhat between studies, the reported cancer detection rates range from 10.0 to 18.1 per 1000 examinations $[15,19,20,22,23]$, which are higher than the overall cancer detection rate in our study. One possible explanation is that $37.9 \%$ of our study population underwent mastectomy, whereas the majority of patients underwent breast conservation surgery in most studies $[11,15,22]$. Another possible explanation is that the majority $(88.1 \%)$ of our study population had previously

Table 3 Clinical and Imaging Characteristics of the Four Intramammary Breast Cancers Detected on Surveillance Breast MRI

\begin{tabular}{|c|c|c|c|c|c|c|c|c|c|}
\hline $\begin{array}{l}\text { Age range, } \\
\text { years }\end{array}$ & $\begin{array}{l}\text { Initial surgery } \\
\text { interval }^{a}\end{array}$ & $\begin{array}{l}\text { Prior } \\
\text { MRI }\end{array}$ & $\begin{array}{l}\text { Side of } \\
\text { Lesion }\end{array}$ & $\begin{array}{l}\text { MRI } \\
\text { assessment }\end{array}$ & $\begin{array}{l}\text { Biopsy } \\
\text { Method }\end{array}$ & Pathology & $\begin{array}{l}\text { MRI } \\
\text { finding }\end{array}$ & $\begin{array}{l}\text { Mammographic } \\
\text { density }\end{array}$ & $\begin{array}{l}\text { Mammography } \\
\text { assessment }\end{array}$ \\
\hline $35-40$ & 60.0 & Yes & Contralateral & BI-RADS 3 & US & IDC & Mass & $\begin{array}{l}\text { Heterogeneously } \\
\text { dense }\end{array}$ & BI-RADS 1 \\
\hline $50-55$ & 56.3 & Yes & Contralateral & BI-RADS 4 & US & DCIS & Nonmass & $\begin{array}{l}\text { Heterogeneously } \\
\text { dense }\end{array}$ & BI-RADS 2 \\
\hline $45-50$ & 24.7 & Yes & Contralateral & BI-RADS 4 & US & $\begin{array}{l}\text { Mucinous } \\
\text { carcinoma }\end{array}$ & Nonmass & $\begin{array}{l}\text { Heterogeneously } \\
\text { dense }\end{array}$ & BI-RADS 2 \\
\hline $35-40$ & 38.7 & Yes & Contralateral & BI-RADS 4 & MRI & ILC & Nonmass & $\begin{array}{l}\text { Heterogeneously } \\
\text { dense }\end{array}$ & BI-RADS 2 \\
\hline
\end{tabular}

IDC invasive ductal carcinoma, DCIS ductal carcinoma in situ, ILC invasive lobular carcinoma

${ }^{a}$ Interval between initial surgery and screening breast MR examination by which the subsequent cancer was detected (months) 


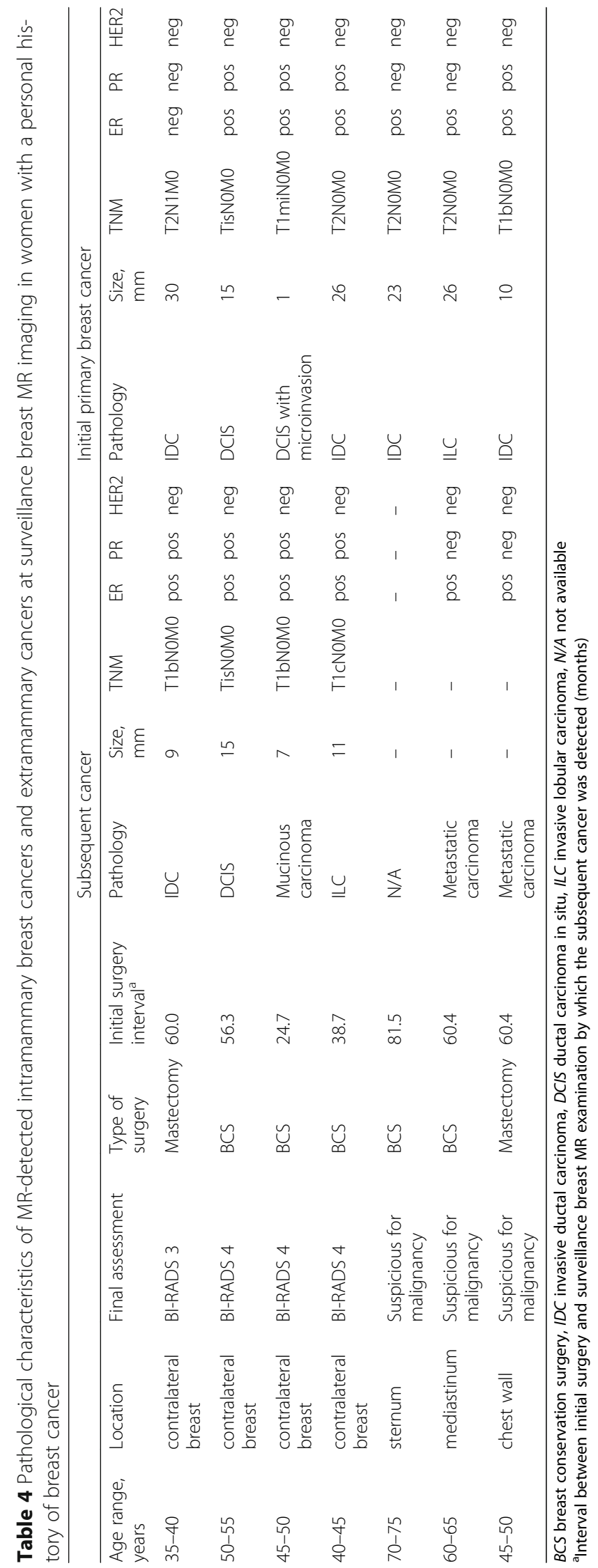


undergone preoperative breast MR imaging, whereas only $38.9 \%$ and $54.2 \%$ of the study population in the study of Brennan et al. and Lehman et al. had baseline preoperative MR examinations, respectively $[19,22]$. In addition, our study population had received routine supplemental surveillance US, with a median interval of 6.1 months between prior surveillance US and MR imaging. All of the four MR-detected intramammary cancers in our study were not detected by previous surveillance US performed prior to MR imaging. Therefore, the MR-detected cancers in our study are more likely to represent truly newly developed cancers after treatment of initial breast cancer, which may be difficult to detect with surveillance US.

The fact that the cancer detection rate for MR imaging performed at more than 3 years after surgery (17.4 per 1000) was greater than that for examinations performed within 3 years (1.41 per 1000) may provide a basis for establishing guidelines regarding timing of surveillance MR imaging initiation following definitive breast cancer surgery. Our overall cancer detection rate was similar to the incidence cancer detection rate of screening breast MR imaging in average risk women in a recent study (7.5 per 1000 examinations, 13 of 1741) [24]. In another study on women with a history of breast conservation therapy, of whom $91.8 \%$ underwent preoperative MR imaging and all had undergone supplemental surveillance US, a more than 24-month interval between initial surgery and MR imaging was an independent factor associated with MR-detected cancers [15]. Similar results have been reported for breast MR imaging screening of women with average risk of breast cancer, with no screening-detected breast cancer diagnoses made until almost 3 years after a negative MR study [24]. This has important implications for the effective implementation of breast MR imaging as a surveillance modality in the future, as breast MR imaging early in the post-treatment surveillance period may have relatively low cancer yields - especially with the increased use of preoperative breast MR imaging.

The overall abnormal interpretation rate $(8.0 \%)$ in our study was slightly lower than prior studies, which ranged from $10.7 \%$ to $19.3 \%$ [15, 20, 22, 25]. Although the PPV (5.3\%) was slightly lower than that in previous MR imaging studies (approximately 9.4\%) [15, 20], it was still higher than mammographic screening benchmarks from 2004 to 2008 according to the Breast Cancer Surveillance Consortium (4.3\%) [26]. In addition, the $\mathrm{PPV}_{3}$ in our study for intramammary lesions, $15.8 \%$ (3 of 19), was higher than the lower range of reported PPV values of surveillance US in women with a personal history of breast cancer, which ranged from $9.4 \%$ to $52.6 \%$ [27-30]. Reported PPV values of surveillance breast MR imaging in women with a personal history of breast cancer have been consistently similar to or higher than that of surveillance US [27-30]. Furthermore, surveillance
MR imaging detected three extramammary rcancers (0.3\%, 3 of 1053), which accounted for $42.8 \%$ of MRdetected cancers. Therefore, breast MR imaging may be more advantageous compared to US as an adjunctive surveillance tool, considering its low abnormal interpretation rate and ability to detect extramammary malignancy.

Our study had several limitations. First, this was a retrospective study from a single institution. Although our institution recently implemented breast MRI imaging into our post-treatment surveillance protocol to be performed two and five years after surgery, MR imaging was also performed at the request of clinicians or patients and therefore, the intervals between surgery and MR imaging were variable. Second, patients underwent surveillance with mammography and US prior to MR imaging, which could have affected the true cancer yield of MRI. Third, the median interval between initial breast cancer surgery and first-time surveillance MR examination (30.1 months, range, 12.1-240.2 months) was relatively short.

\section{Conclusions}

Our data suggest that surveillance breast MR imaging may be considered in women with a history of breast cancer, considering the low abnormal interpretation rate and its high diagnostic performance. However, the cancer detection rate was low and implementation may be more effective after more than 3 years after surgery. Further research on the appropriate timing for surveillance breast MR imaging initiation is required, especially in patients who have undergone preoperative breast MR imaging and supplemental surveillance US.

\section{Abbreviations \\ BCS: Breast conserving surgery; BI-RADS: Breast Imaging Reporting and Data System; CDR: Cancer detection rate; MR: Magnetic resonance; PP: Positive predictive value; US: Ultrasound}

\section{Acknowledgements \\ None.}

Funding

None- for all authors.

\section{Availability of data and materials}

Data supporting our findings are presented in the "Results" section. Researchers interested in source data are invited to write to the corresponding author.

\section{Authors' contributions}

$\mathrm{JHY}$ has made substantial contributions to conception and design, has been involved in data collection, interpretation of data, and final approval of version to be published. VYP has made substantial contributions in data collection, data analysis and wrote and revised the paper. EKK has been involved in acquisition and interpretation of data, and in revising the manuscript critically for important intellectual content. MJK has been involved in acquisition of data and critical review of the manuscript. HJM has been involved in data acquisition and revising the manuscript critically for important intellectual content. All authors read and approved the final manuscript. 


\section{Ethics approval and consent to participate}

The study protocol was approved by the Severance Hospital Institutional Review Board (approval number 4-2016-1063). As data were analyzed anonymously, the requirement for informed consent was waived.

\section{Consent for publication}

Not applicable.

\section{Competing interests}

The authors declare that they have no competing interests.

\section{Publisher's Note}

Springer Nature remains neutral with regard to jurisdictional claims in published maps and institutional affiliations.

Received: 12 September 2017 Accepted: 16 January 2018

Published online: 22 January 2018

\section{References}

1. Clarke M, Collins R, Darby S, Davies C, Elphinstone P, Evans V, et al. Effects of radiotherapy and of differences in the extent of surgery for early breast cancer on local recurrence and 15-year survival: an overview of the randomised trials. Lancet. 2005;366:2087-106.

2. Darby S, McGale P, Correa C, Taylor C, Arriagada R, Clarke M, et al. Effect of radiotherapy after breast-conserving surgery on 10-year recurrence and 15year breast cancer death: meta-analysis of individual patient data for 10,801 women in 17 randomised trials. Lancet. 2011;378:1707-16.

3. Khatcheressian JL, Hurley P, Bantug E, Esserman LJ, Grunfeld E, Halberg F, et al. Breast cancer follow-up and management after primary treatment: American Society of Clinical Oncology clinical practice guideline update. J Clin Oncol. 2013;31:961-5.

4. National Comprehensive Cancer Network. Breast Cancer Screening and Diagnosis (Version 1.2016). https://www.nccn.org/professionals/physician_ gls/pdf/breast-screening.pdf. Accessed February 14, 2017

5. Kuhl C, Weigel S, Schrading S, Arand B, Bieling H, Konig R, et al. Prospective multicenter cohort study to refine management recommendations for women at elevated familial risk of breast cancer: the EVA trial. J Clin Oncol. 2010;28:1450-7

6. Kuhl CK, Schrading S, Leutner CC, Morakkabati-Spitz N, Wardelmann E, Fimmers $\mathrm{R}$, et al. Mammography, breast ultrasound, and magnetic resonance imaging for surveillance of women at high familial risk for breast cancer. J Clin Oncol. 2005:23:8469-76.

7. Sardanelli F, Podo F, Santoro F, Manoukian S, Bergonzi S, Trecate G, et al. Multicenter surveillance of women at high genetic breast cancer risk using mammography, ultrasonography, and contrast-enhanced magnetic resonance imaging (the high breast cancer risk italian 1 study): final results. Investig Radiol. 2011;46:94-105.

8. Warner E, Plewes DB, Hill KA, Causer PA, Zubovits JT, Jong RA, et al. Surveillance of BRCA1 and BRCA2 mutation carriers with magnetic resonance imaging, ultrasound, mammography, and clinical breast examination. JAMA. 2004;292:1317-25.

9. Ashkanani F, Sarkar T, Needham G, Coldwells A, Ah-See AK, Gilbert FJ, et al. What is achieved by mammographic surveillance after breast conservation treatment for breast cancer? Am J Surg. 2001;182:207-10

10. Weinstock C, Bigenwald R, Hochman T, Sun P, Narod SA, Warner E. Outcomes Of surveillance for contralateral breast cancer in patients less than age 60 at the time of initial diagnosis. Curr Oncol. 2012;19:e160-4.

11. Cho N, Han W, Han BK, Bae MS, Ko ES, Nam SJ, et al. Breast cancer screening with mammography plus ultrasonography or magnetic resonance imaging in women 50 years or younger at diagnosis and treated with breast conservation therapy. JAMA Oncol. 2017:3:1495-502.

12. Bliss JM, Kilburn LS, Coleman RE, Forbes JF, Coates AS, Jones SE, et al. Disease-related outcomes with long-term follow-up: an updated analysis of the intergroup exemestane study. J Clin Oncol. 2012;30:709-17.

13. Houssami N, Ciatto S. Mammographic surveillance in women with a personal history of breast cancer: how accurate? How effective? Breast. 2010;19:439-45.

14. Lu WL, Jansen L, Post WJ, Bonnema J, Van de Velde JC, De Bock GH. Impact on survival of early detection of isolated breast recurrences after the primary treatment for breast cancer: a meta-analysis. Breast Cancer Res Treat. 2009;114:403-12.
15. Gweon HM, Cho N, Han W, Yi A, Moon HG, Noh DY, et al. Breast MR imaging screening in women with a history of breast conservation therapy. Radiology. 2014;272:366-73.

16. Kim EJ, Kang BJ, Kim SH, Youn IK, Baek JE, Lee HS. Diagnostic performance of and breast tissue changes at early breast MR imaging surveillance in women after breast conservation therapy. Radiology. 2017;284:656-66.

17. Morris E, Comstock C, Lee C. ACR BI-RADS Magnetic Resonance Imaging. In: American College of Radiology, editor. ACR BI-RADS Atlas, Breast Imaging Reporting and Data System. Reston, VA2013.

18. Sickles EA, D'orsi CJ. ACR BI-RADS ${ }^{\circledR}$ follow-up and outcome monitoring. ACR BI-RADS ${ }^{\circledR}$ atlas breast imaging reporting and data system. Reston, VA: American college of Radiology. 2013;

19. Brennan S, Liberman L, Dershaw DD, Morris E. Breast MRI screening of women with a personal history of breast cancer. AJR Am J Roentgenol. 2010;195:510-6.

20. Giess CS, Poole PS, Chikarmane SA, Sippo DA, Birdwell RL. Screening breast MRI in patients previously treated for breast cancer. Diagnostic Yield for Cancer and Abnormal Interpretation Rate Acad Radiol. 2015;22:1331-7.

21. Kim MJ, Kim EK, Kwak JY, Park BW, Kim SI, Sohn J, et al. Role of sonography in the detection of contralateral metachronous breast cancer in an Asian population. AJR Am J Roentgenol. 2008;190:476-80.

22. Lehman CD, Lee JM, WB DM, Hippe DS, Rendi MH, Kalish G, et al. Screening $\mathrm{MRI}$ in women with a personal history of breast cancer. J Natl Cancer Inst. 2016;108

23. Weinstock C, Campassi C, Goloubeva O, Wooten K, Kesmodel S, Bellevance $\mathrm{E}$, et al. Breast magnetic resonance imaging (MRI) surveillance in breast cancer survivors. Spring. 2015;4:459.

24. Kuhl CK, Strobel K, Bieling H, Leutner C, Schild HH, Schrading S. Supplemental breast MR imaging screening of women with average risk of breast cancer. Radiology. 2017;283:361-70.

25. Berg WA, Zhang Z, Lehrer D, Jong RA, Pisano ED, Barr RG, et al. Detection of breast cancer with addition of annual screening ultrasound or a single screening MRI to mammography in women with elevated breast cancer risk. JAMA. 2012;307:1394-404.

26. Breast Cancer Surveillance Consortium. National Cancer Institute. http:// www.bcsc-research.org/statistics/benchmarks/screening/2009/table5.html. Accessed February 16, 2017.

27. Berg WA, Blume JD, Cormack JB, Mendelson EB, Lehrer D, Bohm-Velez M, et al. Combined screening with ultrasound and mammography vs mammography alone in women at elevated risk of breast cancer. JAMA 2008:299:2151-63.

28. Kim HJ, Kwak JY, Choi JW, Bae JH, Shin KM, Lee HJ, et al. Impact of US surveillance on detection of clinically occult locoregional recurrence after mastectomy for breast cancer. Ann Surg Oncol. 2010;17:2670-6.

29. Lee JH, Kim EK, Oh JY, Kwon HC, Kim SH, Kim DC, et al. US screening for detection of nonpalpable locoregional recurrence after mastectomy. Eur J Radiol. 2013;82:485-9

30. Suh YJ, Kim MJ, Kim EK, Moon HJ, Kim SI, Park BW. Value of ultrasound for postoperative surveillance of asian patients with history of breast cancer surgery: a single-center study. Ann Surg Oncol. 2013;20:3461-8.

\section{Submit your next manuscript to BioMed Central and we will help you at every step:}

- We accept pre-submission inquiries

- Our selector tool helps you to find the most relevant journal

- We provide round the clock customer support

- Convenient online submission

- Thorough peer review

- Inclusion in PubMed and all major indexing services

- Maximum visibility for your research

Submit your manuscript at www.biomedcentral.com/submit
Biomed Central 